\title{
DYNAMICS OF RADIOCARBON IN SOILS
}

\section{A. E. CHERKINSKY and V. A. BROVKIN}

Institute of Geography, Russian Academy of Sciences, Staromonetmy 29, Moscow 109017 Russia

ABSTRACT. We present here a model of humus accumulation in recent soils. We have estimated the coefficients of mineralization of humus and humic acid for a typical Chernozem soil. We suggest a technique for calculating the renewal time of soil with specific activity higher than the modern standard and discuss the results for different soils.

\section{INTRODUCTION}

${ }^{14} \mathrm{C}$ analysis is the most important radioisotope method used to reconstruct the dynamics of Holocene and Late Pleistocene natural processes. A complicated problem in interpreting ${ }^{14} \mathrm{C}$ data is the dating of humus in recent soils, because recent soil is an open system. In a soil profile, organic material accumulates over a long period and is renewed continuously during its lifetime. Until now, there has been no clear understanding of the physical meaning of ${ }^{14} \mathrm{C}$ data with regard to the age and dynamics of recent soils and other time-related parameters. Even now, available data suggest that the development of recent soils occurs over thousands of years. We believe that, given information on specific ${ }^{14} \mathrm{C}$ activity in humus, we can infer that a certain soil is not younger than the obtained date. We can also define the rates and duration of humus accumulation and the coefficients of humus mineralization, which can be used for assessing the stability of organic profile types.

\section{METHODS AND DISCUSSION}

We suggest a model of a monogenetic soil under stable conditions of pedogenesis. The model is based on the following assumptions: 1) the soil develops from the surface downward (Dokuchaev 1936) as a result of increased involvement of rocks in humus-forming processes; 2) accumulation of humus in soil starts asynchronously, and the underlying layers are formed later than the overlying ones (they also have different characteristic times of arrival at a stable state); and 3) rates of input of organic debris and of humus mineralization are invariant with time.

Humus and ${ }^{14} \mathrm{C}$ accumulation can be represented by simple differential Equations (1) and (2)

$$
\begin{gathered}
\frac{d^{12} C_{s}}{d t}=K_{h} \cdot{ }^{12} C_{p d}-m^{12} C_{s} \\
\frac{d^{14} C_{s}}{d t}=K_{h} \cdot{ }^{14} C_{p d}-m{ }^{14} C_{s}-\lambda{ }^{14} C_{s}
\end{gathered}
$$

where ${ }^{12} \mathrm{C}_{\mathrm{pd}}$ and ${ }^{14} \mathrm{C}_{\mathrm{pd}}$ are amounts of plant detritus input of ${ }^{12} \mathrm{C}$ and ${ }^{14} \mathrm{C}$, respectively, ${ }^{12} \mathrm{C}_{\mathrm{s}}$ and ${ }^{14} \mathrm{C}_{\mathrm{s}}$ are the content of carbon in the soil, respectively, and $\mathrm{K}_{\mathrm{h}}, \mathrm{m}$ and $\lambda$ are coefficients of humification, mineralization and radioactive ${ }^{14} \mathrm{C}$ decay constant, respectively. Given the specific activity of humus, these equations for dynamic equilibrium, where input $={ }^{14} \mathrm{C}$ decay constant, allows us to calculate the coefficients of humus mineralization. These equations define the correlation of humus and ${ }^{14} \mathrm{C}$ accumulation with time; using the coefficients of correlation, it is possible to establish the duration of the process of humus accumulation. 
TABLE 1. Coefficients of Mineralization of Humus and Humic Acids in a Typical Chernozem Profile

\begin{tabular}{lcrccc}
\hline & & \multicolumn{2}{c}{ Coefficient of mineralization } \\
Layer & Depth & Humus & Humic acid & Humus & Humic acid \\
\hline $\mathrm{AI}_{1}$ & $0-10$ & $430 \pm 110$ & $1000 \pm 40$ & 0.1979 & 0.0939 \\
& $10-20$ & $750 \pm 100$ & $1440 \pm 50$ & 0.1272 & 0.0635 \\
& $30-40$ & $570 \pm 120$ & $2400 \pm 50$ & 0.1692 & 0.0358 \\
$\mathrm{AI}_{2}$ & $50-60$ & $2890 \pm 100$ & $4050 \pm 60$ & 0.0288 & 0.0191 \\
$\mathrm{AB}$ & $70-80$ & $3730 \pm 120$ & $4580 \pm 60$ & 0.0211 & 0.0164 \\
\hline
\end{tabular}

We tested the model using a typical Chernozem; according to Ivanov and Alexandrovsky (1984) and others, this soil meets the conditions specified in our monogenetic soil model. The results are given in Table 1 . Under stationary conditions, these values for humus range from 0.2 to $0.02 \%$ $\mathrm{yr}^{-1}$, practically one order lower than the coefficients of mineralization produced in classical tests (Afanasieva 1966) with permanent fallow (Chernozem plowed annually for $60 \mathrm{yr}$, during which time ${ }^{14} \mathrm{C}$ content decreased). Conditions of the latter tests differ sharply from the stationary ones. Taking the above coefficients of mineralization, we can calculate the time of humus and ${ }^{14} \mathrm{C}$ accumulation in individual Chernozem layers.

Using Equations (1) and (2), and assuming the first approximation that inflow and mineralization of organic material are constant values, we arrive at the expressions below that show correlation of humus and ${ }^{14} \mathrm{C}$ accumulation with time (Equations (3) and (4))

$$
\begin{gathered}
{ }^{12} \mathrm{C}_{\mathrm{s}}=\frac{\mathrm{K}_{\mathrm{h}}}{\mathrm{m}} \cdot{ }^{12} \mathrm{C}_{\mathrm{pd}} \cdot\left(1-\mathrm{e}^{-\mathrm{mt}}\right) \\
{ }^{14} \mathrm{C}_{\mathrm{s}}=\frac{\mathrm{K}_{\mathrm{h}}}{\mathrm{m}+\lambda} \cdot{ }^{14} \mathrm{C}_{\mathrm{pd}}\left[1-\mathrm{e}^{-(\mathrm{m}+\lambda) t}\right] .
\end{gathered}
$$

Computer-based calculations with these equations explain carbon and ${ }^{14} \mathrm{C}$ accumulation in humus and humic acids in $0-10 \mathrm{~cm}$ depth of typical Chernozem. As Figure 1 demonstrates, $50 \%$ of the total humus and ${ }^{14} \mathrm{C}$ (the latter is accumulated slightly more rapidly) accumulate in ca. 350 calendar yr; $95 \%$ of humus accumulates in $1500 \mathrm{yr}$, and of ${ }^{14} \mathrm{C}$, in $1400 \mathrm{yr}$. The most stable and slowly replaced fraction of humus, humic acids, show the following rate of accumulation: $50 \%$ of humus in $750 \mathrm{yr}$, and $50 \%$ of ${ }^{14} \mathrm{C}$ in $650 \mathrm{yr}$; $95 \%$ of the present level of humic acids in this layer were accumulated in $3200 \mathrm{yr}$, and of ${ }^{14} \mathrm{C}$, in $2800 \mathrm{yr}$ from zero-time, and are practically unchanged since then. The difference between ${ }^{12} \mathrm{C}$ and ${ }^{14} \mathrm{C}$ accumulation arises from radioactivity of the latter isotope, so that it accumulates at a slower rate.

Data on ${ }^{14} \mathrm{C}$ in humus and humic acids in the $0-10 \mathrm{~cm}$ layer of typical Chernozem, presented in Figure 2, show variation of ${ }^{14} \mathrm{C}$ age with true time. Thus, the ${ }^{14} \mathrm{C}$ age of humus increases notably only during the first $2000 \mathrm{yr}$ of pedogenesis, and then reaches constant modern values. For the most inert fraction of humic acids, this period of variation of ${ }^{14} \mathrm{C}$ age is $c a .4500 \mathrm{yr}$, followed by the stable state.

Our model works sufficiently well if we assume constant concentration of ${ }^{14} \mathrm{C}$ in the atmosphere and, correspondingly, in the biota that are the primary material for depositing soil organic matter. 

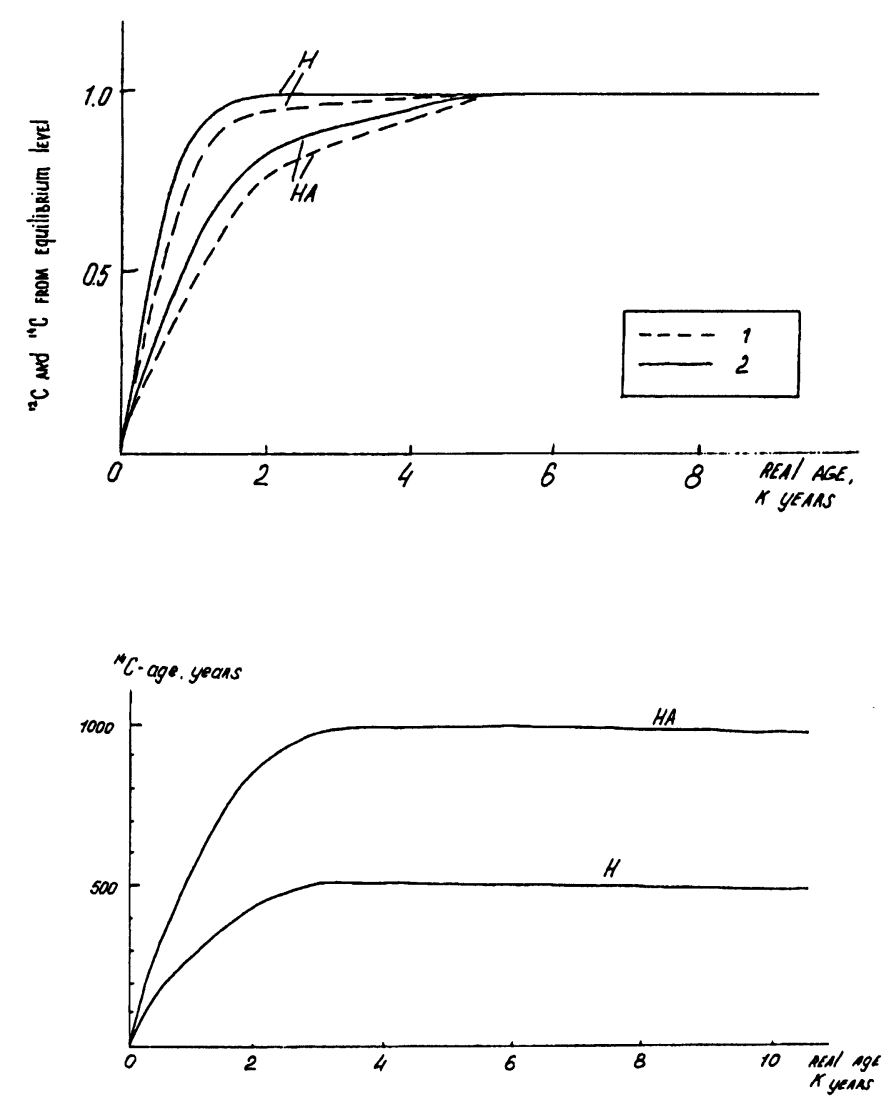

Fig. 1. Accumulation of ${ }^{12} \mathrm{C}(1)$ and ${ }^{14} \mathrm{C}$ (2); humus $(\mathrm{H})$ and humic acid (HA) at $0-10 \mathrm{~cm}$ depth in Chernozem.

Fig. 2. Change in ${ }^{14} \mathrm{C}$ age with true time; humus $(\mathrm{H})$ and humic acid (HA) at $0-10 \mathrm{~cm}$ depth in Chernozem.

However, as many researchers have shown, atmospheric ${ }^{14} \mathrm{C}$ concentrations are not constant, and are affected by explosions of supernovae, variations in solar activity, oscillations of the geomagnetic field, industrial activity and atmospheric nuclear testing. Nuclear power plants also contribute to increased ${ }^{14} \mathrm{C}$ concentration in humus; they generate a significantly higher specific radioactivity for biota than the specific activity of the NIST (formerly NBS) oxalic acid standard. According to our data, this surplus depends little on the type of vegetation and ranges from 130 to $135 \mathrm{pMC}$. This was most pronounced in the humus of soils with short regeneration periods (several decades).

On the basis of our suggested mathematical model of change of specific humus activity, $I(t)$, it is possible to correlate the mean rate of its mineralization with the $I_{o}$ index that is stable for $I(t)$. This correlation can be expressed as

$$
\frac{\mathrm{I}(\mathrm{t})}{\mathrm{I}_{\mathrm{o}}}=\frac{\mathrm{m}}{\mathrm{m}+\lambda}
$$

Atmospheric ${ }^{14} \mathrm{C}$ fluctuations make it impossible to calculate, with Equation (5), the rates of humus mineralization and ${ }^{14} \mathrm{C}$ dates of soils that undergo rapid rejuvenation of carbon. The $\mathrm{I}_{\mathrm{o}}$ index in this equation ceased to be constant in the time interval, 1956-1982. Instead, two stationary levels of specific activity are found: $\mathrm{I}_{\mathrm{o}}^{\prime}$ - "pre-nuclear" activity $(100 \mathrm{pMC})$, and 
I" activity in a soil is, for example, $110 \mathrm{pMC}$, how can this result be interpreted? Calculation of ${ }^{14} \mathrm{C}$ age with Equation (5), if $\mathrm{I}_{0}$ equals $\mathrm{I}_{0}^{\prime}$, gives a negative age. Measurements on the Russian Plain after 1982 to 1990 were ca. 135 pMC. Perhaps this is a result of local emissions. If $\mathrm{I}_{\mathrm{o}}=\mathrm{I}_{\mathrm{o}}$, the measurement provides a date of $c a .1500 \mathrm{yr}$, which disagrees with other ${ }^{14} \mathrm{C}$ data for the soil. The specific activity of the soil is not constant, but gradually increases with time, which disagrees with the assumptions of Equation (5). These difficulties explain why soils with specific activity above $100 \mathrm{pMC}$ are described by specific activity of a sample in percent of the modern standard of prenuclear time, or by the designation "recent" without a date.

We suggest a technique for calculating the ${ }^{14} \mathrm{C}$ age of soils and the rates of humus mineralization that takes into account the whole curve of change of specific activity of atmospheric carbon from 1956 on. We assume that the humus content in a soil is stable, i.e., meeting the condition of equilibrium between humification and mineralization. Then, the dynamics of specific ${ }^{14} \mathrm{C}$ activity in soil humus, $\mathrm{I}(\mathrm{t})$, is calculated as

$$
I(t)=I(t-1)-(m+\lambda) \cdot I(t-1)+m I_{0}(t)
$$

where $I(t-1)$ is the specific activity of humus in the preceding year, and $I_{0}(t)$ is specific activity of atmosphere in the year, $t$. Let us assume that by 1955 the amount of ${ }^{14} \mathrm{C}$ in soil stabilized; then, according to Equation (6), $\mathrm{I}(1955)=\mathrm{I}_{\mathrm{o}} \cdot(\mathrm{m} /(\mathrm{m}+\lambda))$. Thus, given the dynamics of $\mathrm{I}_{\mathrm{o}}(\mathrm{t})$ and the original value of $I(1955)$, Equation (6) can be used to calculate the pattern of change of $I(t)$. If the specific activity was measured in a year, $t_{0}$, and equals $I\left(t_{0}\right)$, it is possible, by changing $\mathrm{m}$, to select the rate of humus mineralization that agrees with $\mathrm{I}\left(\mathrm{t}_{\mathrm{o}}\right)=\tilde{\mathrm{I}}\left(\mathrm{t}_{\mathrm{o}}\right)$ (if $\tilde{\mathrm{I}}\left(\mathrm{t}_{\mathrm{o}}\right)<$ $\left.\mathrm{I}_{\mathrm{o}}^{\prime \prime}\right)$. We can show that the task has a single solution: each $\tilde{\mathrm{I}}\left(\mathrm{t}_{\mathrm{o}}\right)$ corresponds to a single value of the rate of mineralization. Thus calculated, $\mathrm{m}$ in Equation (5) can be used to measure the specific activity of a soil up to 1955 . Thus, the suggested technique allows us to calculate (reconstruct) the true ${ }^{14} \mathrm{C}$ age of a soil and the rate of humus mineralization with the specific activity of humus in the year, $\mathrm{t}_{0}$.

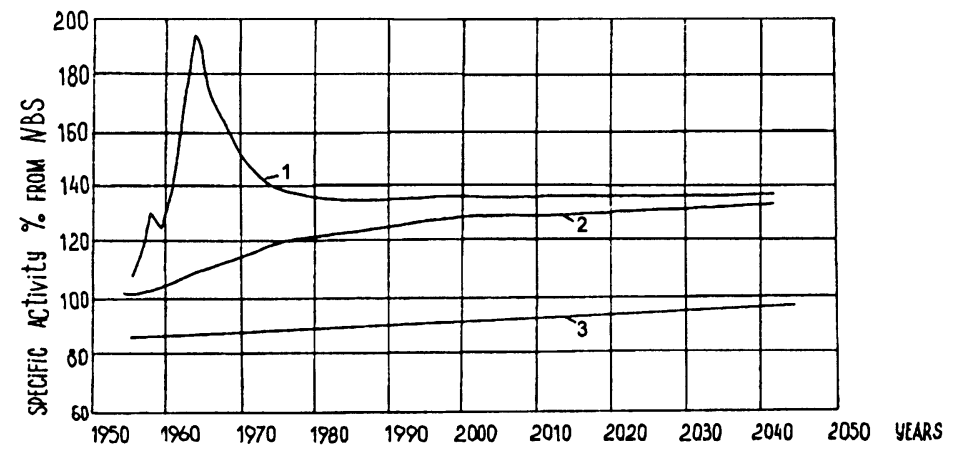

Fig. 3. Calculated change of specific carbon activity in the atmosphere (1) and soil humus with $\mathrm{m}=2.2 \%$ per year (2) and $\mathrm{m}=0.1 \% \mathrm{yr}^{-1}(3)$

For example, the dynamics of the specific humus activity, $I(t)$, in a soil with rapid rejuvenation of organic material at the rate of mineralization of $2.2 \% \mathrm{yr}^{-1}$ is shown in Figure 3, which also demonstrates the curve of change of the specific activity of atmospheric ${ }^{14} \mathrm{C}$ after Bolin (1986). The original specific activity of soil is $99.8 \%$, and rapidly increases because of the high activity of the newly formed humus. In three years, $\mathrm{I}(\mathrm{t})$ becomes more than $100 \%$, prohibiting calculations with Equation (5). The new stationary value of the specific activity of soil is $133.8 \%$. 
In a soil with a low rate of humus mineralization $\left(\mathrm{m}=0.1 \% \mathrm{yr}^{-1}\right)$, the specific activity changes much more slowly (Fig. 3). Thus, from 1950 to 1985 , I(t) changed from $89.0 \%$ to $90.2 \%$, and by 2000 , it will be up to $90.7 \%$. The stationary value, $\mathrm{I}_{\mathrm{o}}(\infty)$, is $119.7 \%$. Because of the slow change of $I(t)$, Equation (5) can be used for some time for calculations, although it will produce an error towards the increased rate of mineralization. Thus, for 1985, the error of $\mathrm{m}$ measurement is $15 \%$ (i.e., $\left.0.015 \% \mathrm{yr}^{-1}\right)$, and in $2000,20 \%\left(0.02 \% \mathrm{yr}^{-1}\right)$. This explains the time-specific use of Equations (5) and (6). The reconstructed rates and ages of different soils are shown in Table 2.

TABLE 2. Radiocarbon Dating of Humic Acids in the Upper Horizons of Some Recent Soils Using Data on Modern ${ }^{14} \mathrm{C}$ Atmospheric Concentrations

\begin{tabular}{lcccc}
\hline \multicolumn{1}{c}{ Soil } & Depth & $\begin{array}{c}\text { Year of } \\
\text { sampling }\end{array}$ & $\begin{array}{c}\text { Specific activity of } \\
\text { humic acid (pMC) }\end{array}$ & $\begin{array}{c}\text { Calculated } \\
{ }^{14} \mathrm{C} \text { date }\end{array}$ \\
\hline $\begin{array}{l}\text { Arctic tundra } \\
\begin{array}{l}\text { Podzol, southern tundra } \\
\text { Soddy-carbonaceous }\end{array}\end{array}$ & $0-4$ & 1988 & $99.36 \pm 1.48$ & $350 \pm 70$ \\
$\begin{array}{l}\text { leached, northern taiga } \\
\text { Soddy-Podzolic, southern }\end{array}$ & $1-8$ & 1986 & $100.05 \pm 1.64$ & $315 \pm 70$ \\
taiga & $2-8$ & 1985 & $107.23 \pm 0.72$ & $125 \pm 40$ \\
$\begin{array}{l}\text { Gray forest, broad-leaved } \\
\text { forest }\end{array}$ & $1-6$ & 1984 & $118.25 \pm 2.04$ & $45 \pm 10$ \\
$\begin{array}{l}\text { Southern Chernozem, dry } \\
\text { steppe }\end{array}$ & $0-7$ & 1980 & $104.25 \pm 0.32$ & $155 \pm 10$ \\
$\begin{array}{l}\text { Chestnut, dry steppe } \\
\text { Krasnozem, humid sub- } \\
\text { tropics }\end{array}$ & $0-10$ & 1983 & $108.03 \pm 0.72$ & $120 \pm 40$ \\
$\begin{array}{l}\text { Cinnamonic, dry sub- } \\
\text { tropics }\end{array}$ & $0-5$ & 1985 & $100.34 \pm 1.74$ & $290 \pm 70$ \\
\hline
\end{tabular}

\section{CONCLUSION}

Soil ${ }^{14} \mathrm{C}$ data do not accurately reflect the age of the soil. However, we can use the dates to determine the time of rejuvenation of humus or its fractions. ${ }^{14} \mathrm{C}$ data for fossil soil determine the time of burial as well as the time of humus rejuvenation. Our model allows us to calculate humus rejuvenation time for soils that have higher specific activity than the modern standard.

\section{REFERENCES}

Afanasieva, E. A. 1966 Chernozems of the Mid-Russian Upland. Moscow, Nauka: $224 \mathrm{p}$.

Bolin, B. 1986 How much $\mathrm{CO}_{2}$ will remain in the atmosphere? The carbon cycle and projections for the future. In Bolin, B., Doos, B. R., Jager, J. and Warrick, R. A., eds., The Greenhouse Effect, Climatic Change and Ecosystems. SCOPE Report 29. New
York, John Wiley \& Sons: 157-203.

Dokucheav, V. V. 1936 Our Steppes Today and Before. Moscow, Selkhozgiz: 117 p.

Ivanov, I. V. and Alexandrovsky, A. L. 1984 The Methods of Studying Soil Evolution and Age. Reprint of the Scientific Center of Biological Researches, Putchino: $51 \mathrm{p}$. 